\title{
OPTIMASI BIAYA PENGIRIMAN BERAS MENGGUNAKAN MODEL TRANSPORTASI METODE NORTH WEST CORNER (NWC) DAN SOFTWARE LINGO
}

\author{
Lusi Mustika Safari ${ }^{1}$, Muhamad Syafi'i Ceffi ${ }^{2}$,Muliadi Suprapto ${ }^{3}$ \\ Program Studi Teknik Industri \\ Universitas Widyatama \\ Jl. Cikutra no.204A, Bandung \\ lusi.mustika@widyatama.ac.id ${ }^{1}$, muhamad.syafii@widyatama.ac.id ${ }^{2}$, muliadi.suprapto@widyatama.ac.id ${ }^{3}$
}

\begin{abstract}
Abstrak
Permasalahan transportasi biasanya berhubungan dengan pendistribusian barang dan jasa dari berbagai sentra produksi ke beberapa lokasi penjualan atau konsumen. Sampel merupakan data biaya pengiriman beras dari Distributor Beras $\mathrm{X}$ di daerah Kab. Karawang. Sampel tersebut kemudian diolah menggunakan metode transportasi dengan metode North West Corner (NWC) dan Software Lingo untuk mengetahui cara meminimumkan biaya setiap kali pengiriman barang. Distribusi barang berkaitan erat dengan kegiatan transportasi yang memadai. Salah satu solusi program liniear dalam pendistribusian barang adalah dengan menggunakan metode transportasi, supaya pendistribusian barang berjalan efektif dengan pengalokasian biaya yang minimum. Harapan dari dilakukannya perhitungan tersebut agar distributor dapat mengetahui biaya yang minimum untuk setiap kali pengiriman barang pada konsumen.
\end{abstract}

Kata kunci: metode transportasi, metode North West Corner (NWC), Software Lingo, distribusi.

\begin{abstract}
Transportation problems usually relate to the distribution of goods and services from various production centers to several sales or consumer locations. The sample is data on the cost of shipping rice from the Rice Distributor $\mathrm{X}$ in the Karawang district. The sample is then processed using the transportation method with the North West Corner (NWC) method and Lingo Software to find out how to minimize the cost of each shipment of goods. Distribution is closely related to adequate transportation activities. One of the linear program
\end{abstract}

solutions in the distribution of goods is to use the method of transportation, so that the distribution of goods runs effectively with a minimum allocation of costs. The expectation of doing these calculations so that distributors can find out the minimum cost for each delivery of goods to consumers.

Key words: transportation method, North West Corner (NWC) method, Lingo Software, distribution.

\section{Pendahuluan}

Secara umum arti transportasi adalah adanya perpindahan barang dari satu tempat ke tempat lain dan dari beberapa tempat ke beberapa tempat lain. Tempat atau tempat-tempat asal barang disebut juga dengan istilah sumber atau sumber-sumber (resources). Sedangkan tempat atau tempat-tempat tujuan disebut destination. Hal ini merupakan bagian dari kehidupan nyata manusia untuk memindahkan barang dari tempat satu ke tempat yang lain sesuai kebutuhannya. Misalnya, di suatu tempat asal barang mempunyai jumlah produk yang berlebih sehingga perlu ditransportasikan ke tempat lain yang memerlukannya (Prawirosentono, 2005).

Penerapan metode transportasi yang tepat selain berguna untuk memperlancar pendistribusian, memaksimalkan pengalokasian dari tempat sumber ke tempat tujuan, juga berguna dalam usaha menekan total biaya transportasi. Diterapkannya suatu metode transportasi, biaya-biaya yang tidak perlu dapat dihilangkan, pengiriman barang dapat berjalan dengan lancar, serta meningkatkan efisiensi perusahaan. Pada dasarnya perhitungan biaya transportasi dengan menggunakan metode transportasi berupaya untuk memecahkan persoalan dari sumber barang dikirim ke 
tempat tujuan sehingga akan dapat diperoleh jumlah biaya angkut yang paling optimal dan memaksimalkan keuntungan (Prihastuti, 2012).

Setiap distributor beras $\mathrm{X}$ di Kab. Karawang memasok beras pada setiap agen dan agen tersebut mendistribusikan beras kepada pelanggannya dengan jumlah beras sesuai dengan permintaan dari masingmasing pelanggan di pasar. Pengiriman beras dari agen ke 4 titik pasar tersebut memiliki biaya transportasi yang berbeda-beda disesuaikan dengan jarak pengiriman dalam setiap kali pengiriman beras.

Biaya transportasi merupakan masalah yang sering dijumpai di berbagai bidang terutama yang bergerak di bidang produksi dan pemasaran. Keputusan yang tepat dalam mengalokasikan produk berdasarkan permintaan dan penawaran dengan memperhatikan biaya distribusi sehingga memperkecil biaya pengeluaran dan akan mencapai keuntungan maksimal dengan mengeluarkan biaya seminimal mungkin. Masalah yang dihadapi oleh distributor beras ini yaitu biaya dalam seklai pengiriman beras ke setiap agennya dengan biaya transportasi yang berbeda-beda, terkadang biaya sekali pengirimannya bisa melonjak naik dan bisa menurun. Distributor beras ini menginginkan biaya pengiriman beras menurut jarak tempuhnya akan tetapi dengan biaya yang minimum dan stabil, maka dengan adanya penggunaan model transportasi dengan metode North West Corner (NWC) dan Software Lingo ini agar distributor dapat menghemat biaya dalam setiap kali pengiriman beras ke setiap pelanggannya.

Untuk meminimalkan biaya transportasi di perlukan metode perhitungan yang tepat sehingga dapat memberikan solusi yang optimal. Metode transportasi merupakan suatu metode yang digunakan untuk mengatur distribusi dari sumber (supply) ke tujuan (demand) dengan alokasi produk yang diatur sedemikian rupa sehingga didapat biaya yang optimal.

\section{I.1 Batasan Masalah}

Untuk memfokuskan penelitian dan memperjelas penyelesaian agar lebih mudah di pahami, maka dilakukan pembatasan masalah sebagai berikut:

1. Ongkos transportasi hanya untuk pengiriman barang.

2. Analisa hanya dilakukan menggunakan model transportasi dengan metode North West Corner (NWC) dan Software Lingo.
3. Menggunakan Software Lingo untuk mendapat hasil yang sangat optimal.

\section{I.2 Tujuan Penelitian}

Tujuan dari penelitian ini adalah:

1. Menjelaskan langkah-langkah menggunakan Metode North West Corner (NWC) dan Software Lingo.

2. Menghitung Biaya Optimal untuk distribusi beras dari agen (supply) ke pasar (demand) dengan menggunakan metode North West Corner (NWC) dan Software Lingo.

\section{I.3 Manfaat Penelitian}

Manfaat yang diharapkan dari penelitian adalah :

1. Agar pembaca dapat mengetahui bagaimana langkah-langkah menggunakan metode North West Corner (NWC) dan Software Lingo.

2. Dapat memberikan penghematan biaya transportasi dalam hal pendistribusian dalam kasus ini khususnya pendistribusian beras.

3. Dapat menghilangkan resiko terjadinya kerugian pada perusahaan sehingga menghasilkan kentungan pada perusahaan.

Hasil yang diharapkan dari perhitungan biaya optimasi pengiriman beras dari distributor ke tiga agen dan beberapa pasar dengan model transportasi menggunakan metode North West Corner (NWC) dan Software Lingo yaitu diharapkan distributor dapat mengetahui optimasi biaya yang minimum saat pengiriman barang, sehingga tidak terjadinya kerugian biaya untuk setiap satu kali pengiriman barang.

\section{LANDASAN TEORI}

\section{II.1 Metode Transportasi}

Model transportasi pada dasarnya merupakan sebuah program linier yang dapat dipecahkan dengan metode simpleks biasa. Tetapi strukturnya yang khusus memungkinkan pengembangan sebuah prosedur pemecahan yang disebut teknik transportasi yang lebih efisien dalam perhitungan (Tahta, 1996). Permasalahan transportasi berkaitan dengan pendistribusian beberapa komoditas dari beberapa pusat penyediaan, yang disebut dengan sumber menuju ke beberapa pusat penerima yang disebut tujuan, dengan maksud untuk 
memperkecil total biaya distribusi (Hillier dan Lieberman, 2001).

\section{II.2 Ciri-ciri Metode Transportasi}

Transportasi memiliki ciri-ciri khusus. Berikut ciri-ciri khusus daritransportasi (Rinaldi, 2005):

1. Terdapat sejumlah sumber dan sejumlah tujuan tertentu

2. Jumlah yang didistribusikan dari setiap sumber dan yang diminta oleh tujuan tertentu.

3. Jumlah yang dikirim dari suatu sumber ke suatu tujuan sesuai dengan permintaan atau kapasitas sumber. Jumlah permintaan dan penawaran seimbang dan apabila jumlah permintaan tidak sama dengan penawaran, maka harus ditambahkan variabel dummy.

4. Biaya transportasi dari sutau sumber ke sutau tujuan yaitu tertentu.

5. Jumlah variabel dasar $m+n-1$, dimana $m$ adalah jumlah baris dan $\mathrm{n}$ adalahjumlah kolom. Apabila jumlah variabel dasar kurang dari $m+n-1$ yang disebut dengan degenerasi, maka harus ditambahkan variabel dasar dengan nilai nol.

\section{II.3 Metode North West Corner (NWC)}

Metode North West Corner (NWC) adalah salah satu metode transportasi yang paling mudah dilakukan, tetapi hasilnya belum tentu optimal. Metode North West Corner $(N W C)$ ini, sumber dan lokasi tujuan diurutkan dari sisi kiri ke kanan dan dari atas ke bawah dalam peta data matriks. Cara penghitungan biaya transportasi dengan menggunakan metode NWC sesuai dengan namanya dimulai dari sisi kiri atas, kemudian bergerak ke kiri atau ke bawah sesuai dengan kapasitas produksi sumber (supply) dan atau permintaan tujuan (demand). Aturan yang berlaku pada metode North West Corner $(N W C)$ ini adalah sebagai berikut :

1. Menghabiskan persediaan di tiap baris sebelum bergerak menuju ke baris selanjutnya yang berada di bagian bawahnya.

2. Memenuhi syarat permintaan di tiap kolom sebelum bergerak menuju ke kolom selanjutnya yang berada di sebelah kanannya.

3. Melakukan cek agar semua persediaan dan permintaan sesuai jumlahnya.

\section{II.4 Kelebihan dan kekurangan metode North West Corner (NWC) :}

a) Kelebihan:

1. Metode yang paling mudah untuk langkah awal perhitungan mencari solusi optimal, tapi tidak mempertimbangkan biaya.

b) Kelemahan:

1. Metode ini tidak hanya untuk mencari solusi awal perhitungan saja, tidak langsung menemukan solusi yang langsung optimal.

2. Metode ini hanya mengalokasikan produk berdasarkan kriteria sudut kiri atas dan sudut kanan bawah ialah yang merupakan sel basis. Metode North West Corner (NWC) kurang efisien dan metode ini merupakan metode terpanjang dalam mencari tabel optimal.

\section{II.5 Software Lingo}

Software Lingo adalah alat bantu yang didesain sangat luas untuk menyelesaikan permasalahan-permasalahan riset operasi seperti program linier dan non linier, kuadratik, quadratically constrained, stokastik dan optimasi model integer dengan lebih cepat, mudah dan efisien. Software Lingo menyediakan paket integrasi lengkap yang termasuk di dalamnya yaitu bahasa untuk optimasi model yang mudah dipahami. Memperhatikan biaya per unit, metode North West Corner (NWC) kurang efisien dan merupakan metode terpanjang dalam mencari tabel optimum. Sebuah optimasi terdiri dari tiga bagian utama yaitu:

1. Fungsi tujuan yaitu sebuah formula yang mendeskripsikan apa yang harus dioptimasikan dalam suatu model. Sebagai contoh, fungsi tujuan dari suatu model adalah maksimasi keuntungan.

2. Variabel adalah kuantitas yang bisa diubah untuk mengeluarkan hasil yang optimal dari fungsi tujuan.

3. Batasan Formula yaitu yang didefinisikan sebagai nilai pembatas dari suatu variabel.

Adapun hal-hal lain yang perlu diperhatikan dalam pembuatan model di Lingo adalah sebagai berikut:

1. Untuk comment dalam model diinisiasi dengan tanda seru (!) dan akan berwarna hijau. 
2. Lingo menetapkan teks operator dan functions muncul dengan warna biru. Tulisan lainnya akan dimunculkan dengan warna hitam.

3. Setiap statement di Lingo harus diakhiri dengansemi-colon (;).

4. Nama variabel harus diawali dengan huruf (A-Z) dan karakter selanjutnya dapat berupa huruf, angka (0-9), atau underscore (_). Panjang dari nama variabel dapat mencapai hingga 32 karakter.

\section{II.6 Manfaat Software Lingo}

Adapun beberapa manfaat atau keunggulan Software Lingo adalah sebagai berikut:

\section{Pengekspresian}

Model yang mudah Lingo dapat membuat formula untuk permasalahan linier, non linier dan integer secara cepat dengan bentuk yang sangat mudah untuk dibaca dan dipahami. Bahasa permodelan Lingo dapat membuat model yang sangat mirip dengan model matematik yang sering dibuat manual di atas kertas.

2. Pilihan Data Tidak Menyusahkan

Data yang akan diolah melalui Software Lingo bisa merupakan data yang sebelumnya ditulis dalam sebuah database dan spreadsheets. Begitu pula dengan output solusi bisa dikeluarkan dalam bentuk database atau spreadsheet, sehingga pengguna bisa lebih mudah dalam pembuatan laporan sesuai dengan keinginan pengguna.

3. Solver yang Baik

Menggunakan Lingo, pengguna tidak perlu menentukan atau memisahkan solver, karena Lingo akan membaca formulasi yang diberikan dan secara otomatis memilih solver yang tepat.

4. Model yang Interaktif

Pengguna dapat memanggil software Lingo langsung dari Excel Macro atau aplikasi database lainnya. Untuk kasus building turnkey solutions, Lingo memiliki fungsi $D L L$ dan OLE Interfaces yang memungkinkan untuk dapat dipanggil dari aplikasi tertulis yang dimiliki pengguna.

\section{HASIL DAN PEMBAHASAN}

Model transportasi dilakukan dengan metode $N W C$ pada data pengiriman beras bulan Juli 2019. Data tersebut yang kemudian diolah untuk melihat optimasi biaya pengiriman beras. Distributor memasok beras ke 3 agen, setiap agen tersebut mengirim beras kepada pelanggannya dengan jumlah beras sesuai dengan permintaan dari masing-masing pasar pelanggan dan biaya satu kali pengiriman Rp. 1.000 .000 tergantung pada jarak yang ditempuhnya. Berikut data pasokan dan permintaan pada bulan Juli 2019 dengan harga dalam satuan juta :

Tabel 3.1 Data Supply dan Demand Bulan Juli 2019

\begin{tabular}{|c|c|c|c|c|c|}
\hline \multirow{2}{*}{ Dari } & \multicolumn{4}{|c|}{ Tujuan (Pasar) } & \multirow{2}{*}{ Pasokan (Ton) } \\
\hline & 1 & 2 & 3 & 4 & \\
\hline Agen 1 & 8 & 6 & 10 & 9 & 35 \\
\hline Agen 2 & 9 & 12 & 13 & 7 & 50 \\
\hline Agen 3 & 14 & 9 & 16 & 5 & 40 \\
\hline Permintaan (Ton) & 45 & 20 & 30 & 30 & 125 \\
\hline
\end{tabular}

Data di atas kemudian diselesaikan dengan solusi awal menggunakan metode $N W C$ sebagai berikut:

Tabel 3.3 Hasil Metode $N W C$ Iterasi 6

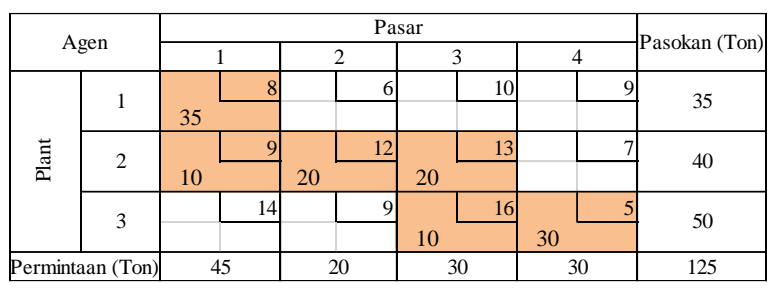

Berdasarkan hasil data yang didapat menggunakan solusi awal $N C W$ yaitu sampai Iterasi ke-6, kemudian didapat jumlah biaya untuk pengirimannya yaitu sebagai berikut:

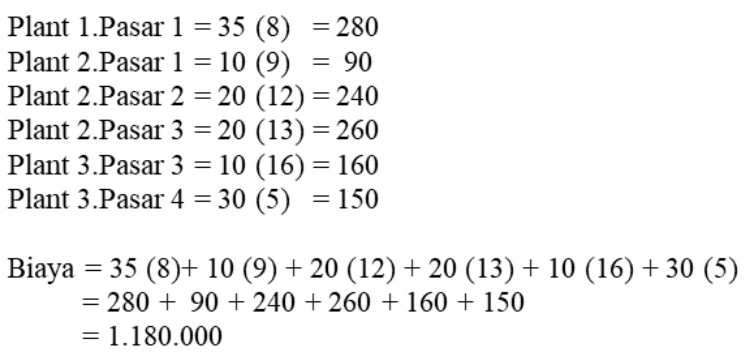

Gambar 3.1 Hasil Solusi Perhitungan Metode NWC 
Berdasarkan dari hasil pencarian solusi awal menggunakan metode North West Corner (NWC) ternyata hasilnya perhitungan tersebut belum optimal dikarenakan metode North West Corner (NWC) hanya perhitungan solusi awal belum solusi optimal, total biaya yang didapatkan yaitu sebesar Rp. 1.180.000, sedangkan distributor menginginkan solusi yang optimal untuk meminimasi biaya ongkos pengiriman beras tersebut. Untuk mengetahui hasil akhir optimalnya dilakukan perhitungan kembali dengan menggunakan Software Lingo. Berikut hasil dari solusi optimal menggunakan Software Lingo:

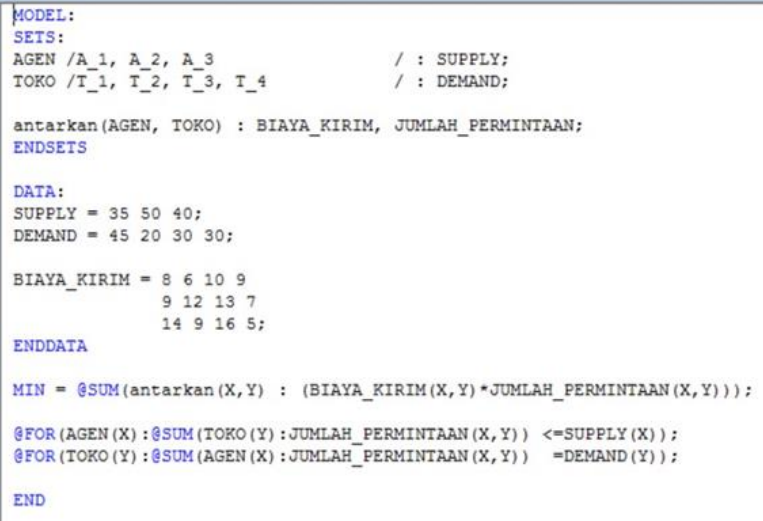

Gambar 3.2 Sintax Lingo

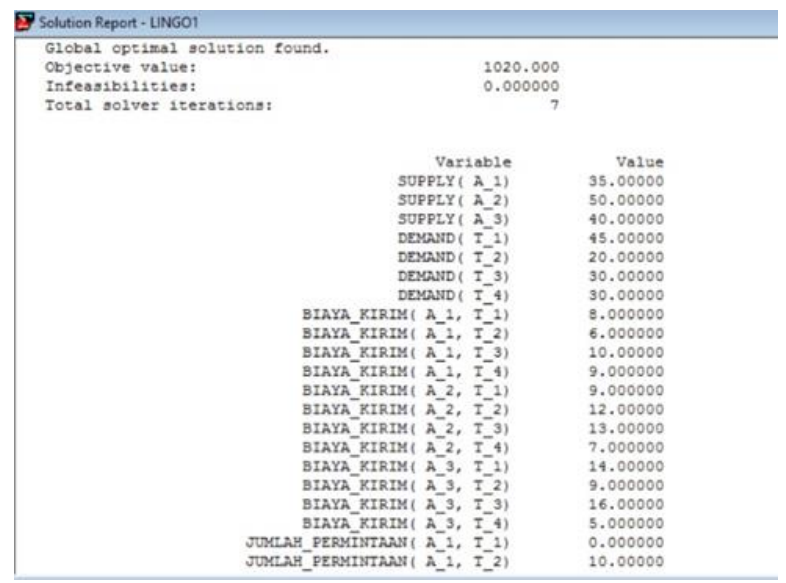

Gambar 3.3 Penyelesaian Solusi Optimal Bagian 1

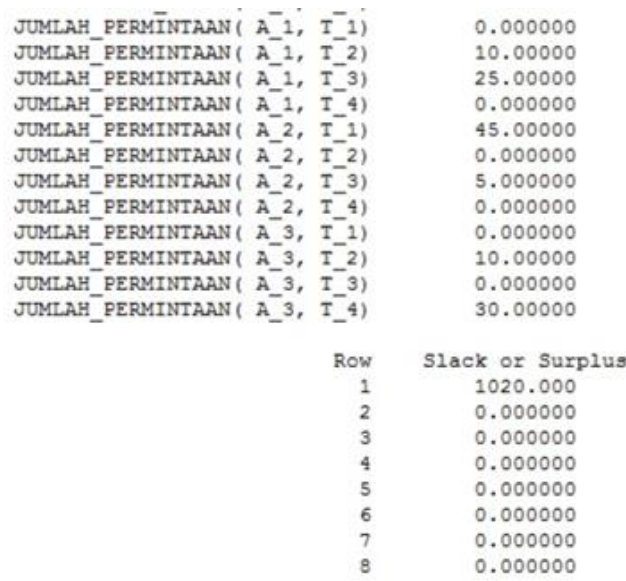

Gambar 3.4 Penyelesaian Solusi Optimal Bagian 2

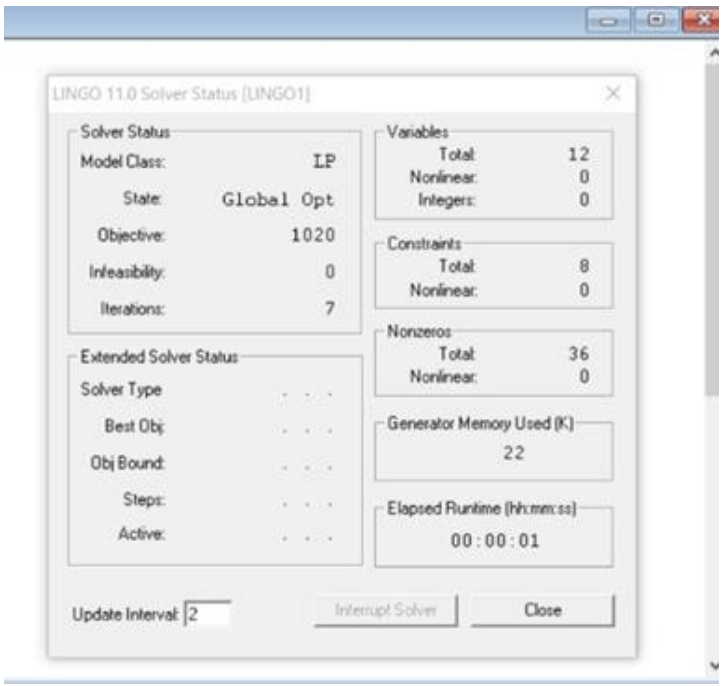

Gambar 3.5 Statuus Penyelesaian Masalah

Bersadarkan hasil dari pencarian solusi optimal menggunakan Software Lingo, mendaptakan hasil yang dapat dikatakan optimal karena hasilnya jauh lebih rendah dibandingkan dengan yang menggunakan metode North West Corner (NWC), walaupun hasilnya tida terlalu jauh beda atau tidak terlalu signifikan. Hasil yang optimal dari penggunaan Lingo yaitu Rp. 1.020 .000 . 


\section{KESIMPULAN}

Penggunaan model transportasi dengan metode North West Corner (NWC) dan Software Lingo dapat diketahui bagaimana menyelesaikan suatu masalah biaya transportasi menggunakan kedua model tersebut. Berikut tabel 4.1 perbandingan hasil dari perhitungan biaya optimal dengan menggunakan kedua metode tersebut :

Tabel 4.1 Hasil Solusi Optimal $N W C$ dan Lingo

\begin{tabular}{|l|c|}
\hline \multicolumn{1}{|c|}{ Metode } & $\begin{array}{c}\text { Hasil Solusi Optimal } \\
\text { (Biaya Ongkos) }\end{array}$ \\
\hline North West Corner $(N W C)$ & Rp. 1.180.000 \\
\hline Software Lingo & RP. 1.020.000 \\
\hline
\end{tabular}

Dari hasil perhitungan dalam tabel diatas dapat disimpulkan bahwa dengan model transportasi dengan menggunakan metode North West Corner (NWC) didapatkan biaya optimal pengirimannya yaitu sebesar Rp. 1.180.000, namun hasil dari perhitungan $N W C$ belum optimal karena North West Corner (NWC) merupakan solusi langkah awal, sehingga perhitungan dilakukan kembali dengan menggunakan Software Lingo dan didapatkan biaya pengiriman yang optimal yaitu sebesar Rp. 1.020.000. Perbedaan dari metode North West Corner (NWC) dan Lingo ternyata hasilnya tidak terlalu signifikan, akan tetapi solusi layak atau optimal akhirnya yang digunakan yaitu menggunakn metode yang memakai Software Lingo.

\section{REFERENSI}

$\mathrm{Bab}$ 2. Landasan Teori. Software Lingo dari https://www.teknologiindustriumi.ac.id/file/2 017/08 MODUL-2-LINGO.pdf pada 09 Maret 2020.

Bab 2. Landasan Teori. Metode North West Corner $(N W C)$ dari https://library.binus.ac.id/eColls/eThesisdoc/ Bab2HTML/2014100183MNBab2001/body.h tml pada 09 Maret 2020.

Oktarido. 2014. Aplikasi Model Transportasi Untuk Optimalitas Distribusi Air Galon Axogy. Universitas Pendidikan Indonesia: Bandung.

Prambudia, Yudha dan Muchammad Fauzi. 2017. Modul Praktikum Manajemen Transportasi dan Distribusi. Universitas Widyatama: Bandung.

Prawirosentono. 2005. Bab 1 Motode Transportasi dari Jurnal Ilmiah Matematika dan Terapan. Universitas Tadulako: Palu

Prihastuti. 2012. Bab 1 Motode Transportasi dari Jurnal Ilmiah Matematika dan Terapan. Universitas Tadulako: Palu

NIM. 2016. Bab 1 Pendahuluan. Universitas Negeri Medan: Medan. 